\title{
agriculture
}

ISSN 2077-0472

www.mdpi.com/journal/agriculture

Article

\section{Rapid Development of Microsatellite Markers for Plantago ovata Forsk.: Using Next Generation Sequencing and Their Cross-Species Transferability}

\author{
Ranbir Singh Fougat ${ }^{1, *}$, Chaitanya Joshi ${ }^{2}$, Kalyani Kulkarni ${ }^{1}$, Sushil Kumar ${ }^{1}$, Anand Patel ${ }^{2}$, \\ Amar Sakure ${ }^{1}$ and Jigar Mistry ${ }^{1}$
}

1 Department of Agriculture Biotechnology, Anand Agricultural University, Anand-388 110, India; E-Mails: kalyaniaau@gmail.com (K.K.); sushil254386@yahoo.com (S.K.); sakure.amar455@gmail.com (A.S.); india.jigar@gmail.com (J.M.)

2 Department of Animal Biotechnology, College of Veterinary Science and Animal Husbandry, Anand Agricultural University, Anand, Gujarat 388 001, India; E-Mails: cgjoshi@aau.in (C.J.); abpate12288@gmail.com (A.P.)

* Author to whom correspondence should be addressed; E-Mail: rsfougat@gmail.com; Tel.: +91-9898-642618; Fax: +91-2692-261134.

Received: 7 February 2014; in revised form: 6 May 2014 / Accepted: 6 June 2014 /

Published: 20 June 2014

\begin{abstract}
Isabgol (Plantago ovata Forsk.) is an important medicinal plant having high pharmacological activity in its seed husk, which is substantially used in the food, beverages and packaging industries. Nevertheless, isabgol lags behind in research, particularly for genomic resources, like molecular markers, genetic maps, etc. Presently, molecular markers can be easily developed through next generation sequencing technologies, more efficiently, cost effectively and in less time than ever before. This study was framed keeping in view the need to develop molecular markers for this economically important crop by employing a microsatellite enrichment protocol using a next generation sequencing platform (ion torrent $\mathrm{PGM}^{\mathrm{TM}}$ ) to obtain simple sequence repeats (SSRs) for Plantago ovata for the very first time. A total of 3447 contigs were assembled, which contained 249 SSRs. Thirty seven loci were randomly selected for primer development; of which, 30 loci were successfully amplified. The developed microsatellite markers showed the amplification of the expected size and cross-amplification in another six species of Plantago. The SSR markers were unable to show polymorphism within $P$. ovata, suggesting that low variability exists within genotypes of $P$. ovata. This study suggests that $\mathrm{PGM}^{\mathrm{TM}}$ sequencing is a rapid and cost-effective tool for developing SSR markers for non-model species, and
\end{abstract}


the markers so-observed could be useful in the molecular breeding of $P$. ovata.

Keywords: isabgol; ion torrent PGM technology; microsatellite; transferability

\section{Introduction}

Plantago ovata Forsk. $(2 n=2 x=8)$, commonly known as Isabgol and blond psyllium, is an important medicinal plant of the family, Plantaginaceae [1]. The seeds are rich in secondary metabolites and contain mucilage, fatty oil, large quantities of albuminous matter, the pharmacologically inactive glucoside viz. aucubin and a plantiose sugar [2]. The husk constitutes $25 \%-30 \%$ (by weight) of the total seed yield and is the most economical part. Their husk has the property of absorbing and retaining water, which accounts for its utility in stopping diarrhea. It is a diuretic, alleviates kidney and bladder complaints, gonorrhea, arthritis and hemorrhoids [3,4]. It is used in food industries for high fiber breakfast cereals. The by-products of dehusking, rich in starch and fatty acids, are used as cattle and pig feed in India. It is also used to prevent ice slipping in factories. Isabgol is a major export-oriented medicinal crop in India [5]. Globally, India is the largest producer, as well as exporter of husk worth more than Rs 25 million annually. From the total production of husk in Gujarat province, $75 \%$ is exported.

In spite of its immense medicinal and export value, the productivity of isabgol is under the constraints of biotic and abiotic stress, causing heavy losses in seed/husk quality and yield. Moreover, due to limited genetic resources, the efforts for generating genetic variability for its improvement are met with limited success [6]. Furthermore, being an introduced crop to India from the Mediterranean region, the variability for economically important traits in the available gene pool is very narrow $[7,8]$. With this low variability, different breeding methods, namely selection, hybridization, induced mutations, polyploidy and tissue culture, have been used for the genetic improvement of isabgol [2,7,9-12]. However, isabgol varieties released through selection so far in India hardly show any phenotypic variations and, hence, are similar in their yield potential. Likewise, the results of other methods of improvement have also not been encouraging.

Plantago ovata has about 200 wild allies, some of which are medicinally important. These wild species are a reservoir of important genes, which if introgressed to cultivated species through marker-assisted breeding could revolutionize the production of isabgol [13]. There are few reports on exploitation of randomly amplified polymorphic DNA (RAPD) [14-16] and combined RAPD and inter-simple sequence repeat (ISSR) [17-19] markers in assessing genetic diversity in isabgol. Equally, a very small number of microsatellite markers are available for other species of Plantago viz. P. major, P. lanceolata, $P$. coronopus and $P$. intermedia [17,20-22]. However, no simple sequence repeat (SSR) markers are available for $P$. ovata. Therefore, researchers are unable exploit the variability available in the secondary gene pool of this crop. Consequently, this industrially important, but resource poor, crop needs attention in terms of developing genetic markers. Microsatellite or simple sequence repeat (SSR) markers, provide a good source for genetic analysis, as proven previously by many researchers [23]. Limited SSR markers with low cross-species transferability are available for Plantago species, but 
none have been developed so far for Plantago ovata. Microsatellites can either be newly developed, especially for a species having limited genomic information, or can be mined from the sequence repositories available in public databases. Various methods are available for microsatellite development, and most of them employ the targeted enrichment of DNA for microsatellites [24]. The recent development of library enrichment techniques, coupled with second-generation sequencing, has made the development of these markers simple, rapid and cost effective. The semiconductor Ion Torrent Personal Genome sequencer carries out sequencing by synthesis (SBS) by sensing the release of hydrogen ions as part of the base incorporation process [25]. The deployment of such a sequencing-based approach drastically reduces the cost of sequencing and can be used to develop molecular markers.

Through the present study, an attempt was made to generate genomic resources in terms of microsatellite markers for Plantago ovata by combining a microsatellite enrichment method with high throughput sequencing along with evaluation of cross-species amplification of the derived markers.

\section{Material and Methods}

\subsection{Germplasm Collection and DNA Extraction}

A total of 12 genotypes, which included six commercially grown varieties of Plantago ovata, and one genotype each from six allied species of $P$. ovata were used in the present study (Table 1). The genotypes were grown in a polyhouse, and young expanding leaves were harvested for DNA isolation. DNA was isolated by the CTAB method [26], checked for quality on $0.8 \%$ agarose gel and quantified using Nanodrop (Thermo Scientific, Wilmington, DE, USA). DNA was diluted to a working concentration of $20 \mathrm{ng} / \mu \mathrm{L}$ with Tris-EDTA buffer and used for PCR amplification.

Table 1. List of Plantago genotypes.

\begin{tabular}{cccl}
\hline $\begin{array}{c}\text { Serial } \\
\text { No. }\end{array}$ & Species & Genotypes & \multicolumn{1}{c}{ Characteristics/Features } \\
\hline & & GI-3 & High yielding, susceptible to downy mildew, aphids, seed shattering \\
& & GI-2 & Susceptible to downy mildew, aphids, seed shattering \\
& & RI-89 & - \\
1 & Plantago ovata & DPO13 & Early maturing mutant \\
& & DPO14 & Early maturing mutant with desirable traits, such as high seed yield, \\
& & & early and uniform seed maturation and high harvest index. \\
& & EC124345 & Resistant to downy mildew; line from Pakistan \\
2 & Plantago arneria & - & Resistant to downy mildew, aphids \\
4 & Plantago coronopus & - & Resistant to downy mildew, aphids, seed shattering \\
5 & Plantago psyllium & - & - \\
6 & Plantago indica & - & Resistant to downy mildew, aphids, seed shattering \\
7 & Plantago serraria & - & - \\
\hline & Plantago lanceolata & - & Resistant to downy mildew, aphids, frost, drought \\
\hline
\end{tabular}

\subsection{Ion Torrent PGM ${ }^{\mathrm{TM}}$ Library Preparation, Enrichment of SSR and Sequencing}

The whole genome sequencing (WGS) library was prepared from $1 \mu \mathrm{g}$ DNA of elite isabgol variety, GI-3 (Gujarat Isabgol-3), following the manufacturer's protocol (Life Technologies, Invitrogen 
Division, Darmstadt, Germany) to obtain a mean size of $200 \mathrm{bp}$. Microsatellite enrichment was performed by hybridizing the genomic DNA library (1:1) with custom designed 5 ' biotinylated di- and tri-nucleotide repeat SSR probes (MWG, Eurofins) (Supplementary file). Hybridization was performed in $2 \times$ hybridization buffer containing 10× SSPE, 10× Denhardt's, $10 \mathrm{~mm}$ EDTA and 0.2\% SDS [27] for $24 \mathrm{~h}$ at $65{ }^{\circ} \mathrm{C}$ followed by enrichment of captured SSR repeats using streptavidin beads (Quiagen, Germany). Captured sequences were eluted and purified using melt solution $(100 \mathrm{~mm} \mathrm{NaOH})$ and a PCR purification kit following the manufacturer's protocol (Quiagen, Venlo, Limburg, Netherlands). The microsatellite enriched or captured library was further amplified for eight cycles using primers complementary to the P1 and A adaptors used for library preparation. An amplified enriched library was purified by Ampure XP beads (Beckman Coulter, Brea, CA, USA) and quantified by an Agilent 2100 bioanalyzer high sensitivity chip (Agilent Technologies, Palo Alto, CA, USA). The SSR captured library was diluted to $26 \mathrm{pM}$ for emulsion PCR to get a $18-\mu \mathrm{L}$ volume of diluted library, and amplification solution (nuclease-free water, 5× PCR Reagent mix, 10× PCR Enzyme Mix and Ion Sphere ${ }^{\mathrm{TM}}$ Particles) was added and amplified in a thermal cycler according to the manufacturer's instructions. The Ion Sphere ${ }^{\mathrm{TM}}$ particles were recovered and enriched using the Ion Xpress Template Kit (Part \#4467389 Rev. B), according to the manufacturer's protocol. Ion sphere particles (ISPs) enrichment was confirmed using the Qubit 2.0 fluorometer (Life Technologies, Invitrogen division, Darmstadt, Germany). The sample ISPs were loaded on an Ion 318 chip and sequenced on the Ion Torrent PGM ${ }^{\mathrm{TM}}$ for 500 flows/ 125 cycles.

The sequencing data was obtained in FASTQ format, which was extracted in the form of FASTA files and subjected further to assembly. Adaptor, poly-A tail trimming and quality filtering (threshold quality score $=20$ ) was performed using the software, DNASTAR. Contigs were assembled using the SeqMan NGen 4.0.0 software package (DNASTAR, Madison, WI, USA) specifying a match spacing of 20 nucleotides and a minimum match percentage of $90 \%$.

\subsection{Searching for SSR-Containing Sequences and Primer Design}

SSRs were mined from the sequence assembly using the Perl-based Microsatellite (MISA) search module [28,29], which is capable of identifying perfect, as well as compound SSRs. The criteria used for the identification of SSRs included a minimum of six repeats for di- $(N N)$ and four repeats for tri-nucleotide $(N N N)$ [30]. Two SSRs separated by a maximum of 100 nucleotide bases were considered as part of a compound SSR. The design of primer pairs for SSRs was done by using Primer3 [31] with default parameters. The primer designing conditions were: $50-60{ }^{\circ} \mathrm{C}$ melting temperature, $40 \%-60 \% \mathrm{GC}$ content and 18-24 bp primer length. Other parameters were at the default setting of Primer3. The designed primers were further checked for desired characteristics, like hairpin structure, primer dimer using the online Scitool, Oligoanalyzer, Integrated DNA Technologies [32]. The newly developed SSR primers were named with the prefix APOM (Anand Plantago ovata microsatellites) and synthesized from First Base, Germany.

\subsection{Validation and Cross-Species Amplification of SSR Markers}

To validate and assess the transferability of the newly identified SSRs, a total of 37 microsatellites were randomly selected. These 37 SSRs were first used to assess polymorphism in Plantago ovata. 
PCR amplification was carried out in a $10-\mu \mathrm{L}$ volume containing $5 \mu \mathrm{L}$ DreamTaq Green PCR Master Mix (2×) (Thermo Scientific/Fermentas, India), $3 \mu \mathrm{L}$ nuclease free water, $0.5 \mu \mathrm{L}$ primer pairs (10 pmol each) and $1 \mu \mathrm{L}$ template DNA $(20 \mathrm{ng} / \mu \mathrm{L})$. Thermal amplification was carried out in a Thermal Cycler (Eppendorf Vapo Protect, Hamburg, Germany) by using the following conditions; initial denaturation at $94{ }^{\circ} \mathrm{C}$ for four min, 35 cycles of denaturation at $94{ }^{\circ} \mathrm{C}$ for $30 \mathrm{~s}$, annealing temperature ranging between $48-60{ }^{\circ} \mathrm{C}$ for $45 \mathrm{~s}$, extension at $72{ }^{\circ} \mathrm{C}$ for one min and final extension at $72{ }^{\circ} \mathrm{C}$ for seven min. The amplified products of SSR were analyzed using $2.5 \%$ agarose gel. The separated amplicons were visualized under a UV transilluminator and photographed using the BioRad Gel Documentation system. The primers showing amplification in $P$. ovata were selected for cross-species amplification with the same conditions as described for P. ovata.

\subsection{Characteristics of Microsatellites, SSR Marker Scoring and Data Analysis}

The microsatellites were classified depending upon the length of the SSR as Class I ( $\geq 20$ nucleotides (nts)) and Class II ( $\geq 10$ but $<20$ nts), the number of nucleotides per repeat unit viz. di- and tri-nucleotide repeats and the arrangement of nucleotides in the repeat motifs viz. perfect repeats, imperfect repeats and compound repeats.

The amplicon profiles of SSR markers generated in Plantago ovata and the six allied species were scored manually as present (1) or absent (0) for each of the SSR loci. Coefficients of similarity were calculated by using Jaccard's similarity coefficient by the SIMQUAL function, and cluster analysis was performed by the agglomerative technique using the UPGMA (un-weighted pair group method with arithmetic mean) method by the SAHN clustering function of NTSYS-pc 2.2 [33]. Relationships between the Plantago species were graphically represented in the form of a dendrogram. The polymorphism information content (PIC) values were calculated according to the following formula: $\mathrm{PIC}=1-\Sigma \mathrm{Pi}^{2}$, where Pi is the frequency of the $\mathrm{i}^{\text {th }}$ allele [34].

\section{Results and Discussion}

\subsection{Sequencing by Ion Torrent PGM ${ }^{\mathrm{TM}}$}

The construction and screening of partial genomic libraries and the sequencing of SSR-positive clones are considered effective methods for microsatellite development [35]. However, these approaches are expensive and labor-intensive processes. Therefore, SSR development through enrichment protocols and next generation sequencing turns out to be more desirable over other methods; being fast and efficient [36]. In particular, the discovery and development of simple sequence repeats (SSRs or microsatellites) is straightforward using NGS technologies [37]. Ongoing improvement in the read lengths of the NGS platforms will reduce the disadvantage of the current short read lengths, particularly for the PGM platform, allowing greater flexibility in primer design coupled with the power of a larger number of sequences. Recently, Elliott et al., 2013 [38] reported that PGM sequencing produced more sequences and a higher number of unique microsatellite sequences than GSFLX sequencing for two gymnosperms and one angiosperm species. In the present study, with the targeted enrichment of DNA for microsatellites development, a total of $176.64 \mathrm{Mb}$ of data and nine, 30 and 940 quality reads were obtained in a single sequencing run from the genomic 
DNA of $P$. ovata with an average read length of $190 \mathrm{bp}$ (Table 2). A total of 249 microsatellites were identified from 3447 contigs, and 37 were randomly used for primer designing. The enrichment procedure thus proved to be an efficient way of generating a large number of SSR loci. The contig sequences are provided as a separate Supplementary file.

Table 2. Summary of PGMTM sequencing and assembly.

\begin{tabular}{ccr}
\hline \multirow{4}{*}{ Sequencing } & Reads & 930,940 \\
& Total bases (bp) & $176,641,378$ \\
& Average read length (bp) & 190 \\
& Highest read length (bp) & 324 \\
\hline & No. of contigs & 3,447 \\
\multirow{3}{*}{ Assembly } & Assembled sequence & 257,993 \\
& Unassembled sequences & 672,947 \\
& Contig N50 (bases) & 1,346 \\
& Average lengths contigs & 659 \\
\hline
\end{tabular}

\subsection{Summary for SSR-Containing Sequences}

The rates of SSR mutation are positively correlated with SSR length [39], and thus, SSRs were divided into two classes based on size (Class I, $\geq 20$ nts; Class II, ( $\geq 10$, but $<20$ nts). SSRs with lengths of 20 nucleotides and greater tend to be highly mutable [40], while SSRs with lengths between 10 and 19 nucleotides tend to be moderately mutable [41]. In the case of this study, Class I ( $\geq 20$ nts) microsatellites were more abundant than in Class II $(\geq 10$, but $<20 \mathrm{nts})$ in the enriched DNA of P. ovata. Taken together, perfect (94\%) repeat motif SSRs dominated over compound repeats (6\%).

Depending on the number of nucleotides per repeat unit, di-nucleotides comprised $11.6 \%$ and tri-nucleotides comprised $88.35 \%$ (Table 3). The tri-nucleotides were the most common SSR type in the Plantago genomic sequence, representing nearly $88 \%$ of all SSRs, followed by dinucleotides (12\%) (Table 3). This higher percentage of trinucleotide SSR in Plantago was almost similar to that of most monocot species (pearl millet, rice and sorghum) and Arabidopsis, which were by far the most frequent repeat type [42]. The results contrast with that of the trinucleotide repeat distribution in poplar, grapevine and cucumber, where tetranucleotides are the most common SSR type $[43,44]$. A possible explanation for the relative abundance of trinucleotides microsatellites in Plantago may rely on the fact that enrichment was performed with a greater number of trinucleotides probes than dinucleotides.

Table 3. Frequency distribution of two repeat types (di- and tri- motif units) microsatellites identified in contigs from the $\mathrm{PGM}^{\mathrm{TM}}$ sequencing of genomic DNA from $P$. ovata.

\begin{tabular}{ccccc}
\hline & Repeat & $\begin{array}{c}\text { Number of Loci } \\
\text { Identified }\end{array}$ & Percentage (\%) & Frequency (\%) \\
\hline Class I & Dinucleotide & 25 & 10.96 & 10.04 \\
$\geq 20 \mathrm{nts}$ & Trinucleotide & 203 & 89.03 & 81.52 \\
Class II & Dinucleotide & 4 & 19.04 & 1.60 \\
$\geq 10$ but $<20 \mathrm{nts}$ & Trinucleotide & 17 & 80.95 & 6.82 \\
\hline
\end{tabular}


In the di-nucleotide repeat category, the distribution of SSRs in different motif types was not uniform, and the most frequent motif type was represented by $\mathrm{CG} / \mathrm{GC}(40 \%)$ and $\mathrm{AC} / \mathrm{GT}(30 \%)$, followed by $\mathrm{AG} / \mathrm{CT}$ and AT/AT (Figure 1). By contrast, the $\mathrm{CG} / \mathrm{GC}$ motif was reported as the least frequent dinucleotide in dicots [45]. This difference may account for different genomes being tested or the use of different SSR isolation strategies with varying affinities [46]. AT repeats were least unlike other reports on the abundance of AT repeats in plant genomes [40]. The high frequency of CG repeats can be ascribed to the high level of heterochromatin present in Plantago species [47]. SSR markers with a GC-rich motif would show higher polymorphism than SSR markers with other dinucleotide motifs [48]. Moreover, taxon-specific accumulation of repeats in eukaryotic genomes has been reported for several species [49]. It can be inferred that the accumulation of CG repeat can be species specific.

Figure 1. Frequency distribution of microsatellites in $P$. ovata based on the di-repeat and tri-repeat motif sequence types.

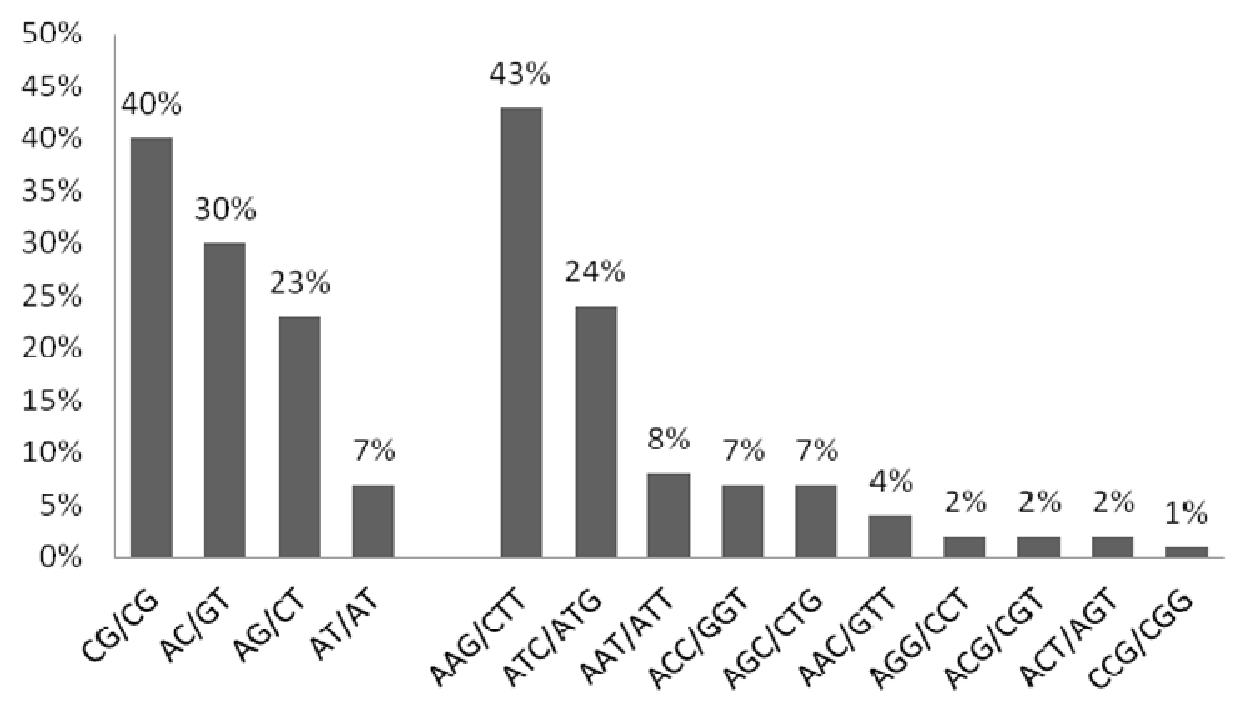

The most frequently occurring microsatellites were $\mathrm{AAG} / \mathrm{CTT}$ and ATC/ATG followed by AAT/ATT, ACC/GGT, AGC/CTG, AAC/GTT, AGG/CCT, ACG/CGT, ACT/AGT and CCG/CGG. In dicots, trinucleotides with repeat motifs AAG/CTT accounted for the highest percentage of total trinucleotide repeats in genomic sequences. The abundance of AAG/CTT and ATC/ATG repeats might be a species-specific feature and related to high frequencies of certain amino acids [50]. In the present study, GGC was the least repeat motif, which was observed more frequently in all of the monocot species and lower plants [51,52]. Trinucleotides with repeat motifs CCG/GGC were dominant only in monocots and contributed to $51.5 \%$ of the total trinucleotide repeats identified in monocots, whereas only $1.9 \%$ of these repeats were present in dicots [45]. This conclusion is supported by the observation that the trimer motif, CCG/CGG, is predominant in the algae, Chlamydomonas reinhardtii, and the model moss, Physcomitrella patens, and could reflect the high GC content in these species. Such a dominance of triplets over other repeats in coding regions may be explained on the basis of the suppression of non-trimeric SSRs in coding regions, possibly due to a change in the reading frame with the increase or decrease in the number of repeat units [50]. 


\subsection{SSR Amplification and Cross-Species Amplification}

Out of the selected 37 primers, 30 showed amplification and generated a total of 32 amplicons in Plantago ovata. Hence, the overall amplification rate was high $(81 \%)$ without any non-specific amplification. The amplicon length ranged from $126 \mathrm{bp}$ (APOM24) to $715 \mathrm{bp}$ (APOM20). All microsatellites genotyped amplified alleles within the expected size range. However, only one or two alleles were observed at each one of the 30 SSRs (Table 4). All microsatellites were monomorphic, displaying a single allele in the $P$. ovata accessions (Figure 2) analyzed in spite of the expected multiallelic nature of these hypervariable markers. The results of the microsatellite analysis in $P$. ovata are well in line with other studies that dealt with RAPD and ISSR [15,19]. The narrow variation and lack of inherent genetic diversity among the different $P$. ovata genotypes has also been revealed by both RAPD and ISSR markers [19,53]. Another important result rendered by the microsatellite analysis is a very high rate of homozygosity in contrast to the preferentially outcrossing mating system for P. ovata. As a protogynous species with a temporal difference in anthesis, it is expected that most loci in P. ovata would be heterozygous, due to the preferential occurrence of outcrossing.

Figure 2. Agarose gel image showing amplification patterns of SSR markers, APOM 23 and APOM 25, among six genotypes of $P$. ovata and allied species. M, 100 bp plus ladder (Thermo Scientific); 1, GI-3; 2: GI-2; 3, RI-89; 4, DPO13; 5, DPO13; 6, EC124345; 7, Plantago arneria; 8, Plantago coronopus; 9, Plantago psyllium; 10, Plantago indica; 11, Plantago serraria, 12, Plantago lanceolata.

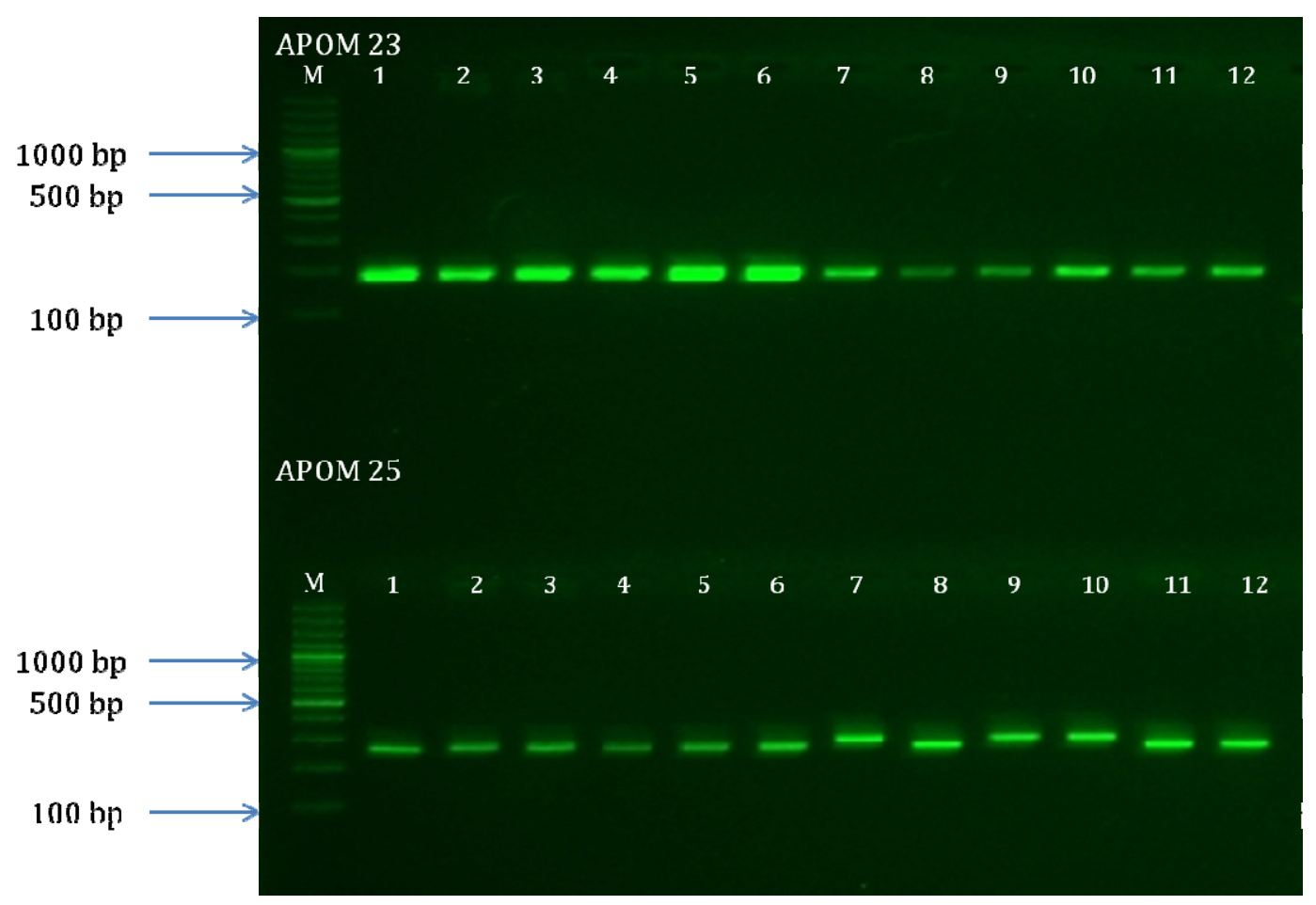


Table 4. Characteristics of the simple sequence repeat (SSR) loci isolated from P. ovata.

\begin{tabular}{|c|c|c|c|c|c|c|c|}
\hline Sr. No & Primer & Primer Sequence $(\mathrm{F} / \mathrm{R})$ & $\mathbf{T m} *$ & Repeat Motif & Amplified Fragment Size & No. of Observed Alleles & PIC ** \\
\hline 1 & APOM 1 & $\begin{array}{l}\text { TGGCACTTGGGCAAATCTACTTGG } \\
\text { TTGGTATCCACGGATGAACAGCCT }\end{array}$ & 60 & GC6 & 235 & 6 & 0.75 \\
\hline 2 & APOM3 & $\begin{array}{l}\text { GTTTACCTTGCTCAAGTGCTTGCT } \\
\text { AACTCCTTCACCCTTCGCCTAACA }\end{array}$ & 52 & TG10 & 301 & 9 & 0.00 \\
\hline 3 & APOM4 & $\begin{array}{l}\text { TGTCACACACACACACACACACAC } \\
\text { AGGGAAACTGCCATGACTCCTCTT }\end{array}$ & 52 & CA10 & 269 & 12 & 0.00 \\
\hline 4 & APOM 5 & $\begin{array}{l}\text { ATGGAAGGAGGGTGGTGGAAGTTT } \\
\text { AGCTTTATCACAGCGACGGAGCTT }\end{array}$ & 52 & AG7 & 377 & 6 & 0.75 \\
\hline 5 & APOM 6 & $\begin{array}{l}\text { AATTGAAGACTGTGCACTTGGGCG } \\
\text { AAAGGAGAGAGAGAGAGAAGCACG }\end{array}$ & 60 & TC7 & 181 & 6 & 0.75 \\
\hline 6 & APOM 7 & $\begin{array}{l}\text { AGGAAGGAGTCCCGAAGAGTAAGA } \\
\text { AAATTGGGACCCACCTATCTCCCGTA }\end{array}$ & 55 & $\mathrm{GC7}$ & 431 & 6 & 0.75 \\
\hline 7 & APOM 8 & $\begin{array}{l}\text { ATCTAACTTATCCCTTGGAC } \\
\text { TGCCTTAGAACTATAAGTGG }\end{array}$ & 52 & GC7 & 140 & 12 & 0.00 \\
\hline 8 & APOM 9 & $\begin{array}{l}\text { TTATATATCCGTCGATTTTC } \\
\text { AAAATATGCACTTGATTAGC }\end{array}$ & 52 & CA10 & 197 & 12 & 0.00 \\
\hline 9 & APOM 10 & $\begin{array}{l}\text { TTATTGATTTCGGATCTTTA } \\
\text { GACACACACAACTTTCTCTC }\end{array}$ & 60 & AG7 & 192 & 12 & 0.00 \\
\hline 10 & APOM 11 & $\begin{array}{l}\text { ATCTAACTTATCCCTTGGAC } \\
\text { TGCCTTAGAACTATAAGTGG }\end{array}$ & 55 & AG6 & 199 & 6 & 0.75 \\
\hline 11 & APOM 12 & $\begin{array}{l}\text { ATTAACTGAGGAAGAGGAAG } \\
\text { AGATTGAGTAGTTTCAGCAA }\end{array}$ & 55 & GAA5 & 212 & 12 & 0.00 \\
\hline 12 & APOM 13 & $\begin{array}{l}\text { CTATTTGTCCTTCTTTGCTA } \\
\text { ATATATCTGACAAGTCGCAC }\end{array}$ & 60 & AGC7 & 245 & 12 & 0.00 \\
\hline
\end{tabular}


Table 4. Cont.

\begin{tabular}{|c|c|c|c|c|c|c|c|}
\hline Sr. No & Primer & Primer Sequence (F/R) & $\mathbf{T m} *$ & Repeat Motif & Amplified Fragment Size & No. of Observed Alleles & PIC * \\
\hline 13 & APOM 14 & $\begin{array}{c}\text { AAATTCTAAGGCTTGTACCT } \\
\text { AAAATTTAGCACGCGA }\end{array}$ & 60 & TTC4 & 249 & 9 & 0.43 \\
\hline 14 & APOM 15 & $\begin{array}{c}\text { ATGGAGTAGGAAGTGAGAGT } \\
\text { GAGATGCATATCTTAAGTGTAG }\end{array}$ & 60 & GAT4 & 183 & 12 & 0.00 \\
\hline 15 & APOM 16 & $\begin{array}{l}\text { CATAGAGTATGCTGGAAAAT } \\
\text { ATTCATGTTCTTGACTGTGT }\end{array}$ & 60 & TCC4 & 190 & 6 & 0.75 \\
\hline 16 & APOM 17 & $\begin{array}{l}\text { TGTAAGGTATTGAGATTGCT } \\
\text { CTTCTAATGATGATGATGGT }\end{array}$ & 55 & GTG5 & 156 & 12 & 0.00 \\
\hline 17 & APOM 19 & $\begin{array}{l}\text { TGCAATGAGTTTTATTCTCT } \\
\text { GATTGTCATCATCTTCATTC }\end{array}$ & 60 & CTC4 & 196 & 6 & 0.75 \\
\hline 18 & APOM 20 & $\begin{array}{c}\text { ATT AAA TTC GTA GTT TGA CAC ATC } \\
\text { ACTTGATCAGTTTGGTAGTG }\end{array}$ & 62 & CTT4 & 715 & 7 & 0.66 \\
\hline 19 & APOM 21 & $\begin{array}{l}\text { AATGTACAAGAAGTTTTCCA } \\
\text { GGAACATATTCCAAGAACTA }\end{array}$ & 58 & TCT4 & 281 & 7 & 0.66 \\
\hline 20 & APOM 23 & $\begin{array}{l}\text { AGCTAGTATCAATGCACAAT } \\
\text { AAGCTACATCATCAGAAGAA }\end{array}$ & 47 & CTT4 & 198 & 12 & 0.00 \\
\hline 21 & APOM 24 & $\begin{array}{l}\text { TTGCTGAAACTACTCAATCT } \\
\text { ATTCTTCTTCAGTATCAGCA }\end{array}$ & 47 & CTG4 & 126 & 6 & 0.75 \\
\hline 22 & APOM 25 & $\begin{array}{l}\text { TCCGGAGTATAATAAGTCAA } \\
\text { ACAATAATGATGTGTTTGGT }\end{array}$ & 47 & TAA5 & 278 & 12 & 0.00 \\
\hline 23 & APOM 27 & $\begin{array}{l}\text { ACATTTTCCAACATTTAAGA } \\
\text { CTAGACCAATAACAGCCTTA }\end{array}$ & 47 & TCA5 & 191 & 11 & 0.16 \\
\hline 24 & APOM 28 & $\begin{array}{c}\text { TCAACCGATGGACAGT } \\
\text { CGTTAATTGTTTGTTTGAAT }\end{array}$ & 47 & GCT4 & 279 & 6 & 0.00 \\
\hline
\end{tabular}


Table 4. Cont.

\begin{tabular}{|c|c|c|c|c|c|c|c|}
\hline Sr. No & Primer & Primer Sequence (F/R) & $\mathbf{T m} *$ & Repeat Motif & Amplified Fragment Size & No. of Observed Alleles & PIC ** \\
\hline 25 & APOM 29 & $\begin{array}{l}\text { CATAGAGTATGCTGGAAAAT } \\
\text { ATTCATGTTCTTGACTGTGT }\end{array}$ & 47 & TTCT4 & 199 & 12 & 0.75 \\
\hline 26 & APOM 30 & $\begin{array}{c}\text { TCAACCGATGGACAGT } \\
\text { CGTTAATTGTTTGTTTGAAT }\end{array}$ & 47 & GCT4 & 279 & 6 & 0.75 \\
\hline 27 & APOM 31 & $\begin{array}{l}\text { CGAGTTATCTTTACTCGATG } \\
\text { TCACCAGTAGTAAGTGGAAG }\end{array}$ & 47 & TGA4 & 192 & 12 & 0.00 \\
\hline 28 & APOM 34 & $\begin{array}{l}\text { GCGACTCCTCCCTATCTTCTTCAT } \\
\text { TTCATCCCAАATCTATCAАTTCACC }\end{array}$ & 57 & AC8 & 273 & 12 & 0.00 \\
\hline 29 & APOM 36 & $\begin{array}{l}\text { AATAAGGGAGGTGCACAGACCGAT } \\
\text { TCCGTGAGCTTCCTTGGACTGAAA }\end{array}$ & 57 & TA6 & 241 & 12 & 0.00 \\
\hline 30 & APOM 37 & $\begin{array}{l}\text { TGGTTTAGGCTTTCCTGCCTTTGC } \\
\text { TTTCCTTCGGCCAAACACTCTTGC }\end{array}$ & 57 & TG7 & 307 & 9 & 0.43 \\
\hline
\end{tabular}

* Tm, temperature melting; ** PIC, polymorphic information content 
SSR primers show cross-genus and cross-species amplification [54,55], and the success of the cross-species amplification of SSRs depends on the evolutionary relatedness of the species sampled [56]. To test the cross-species transferability, 30 SSRs were tested on a panel of six allied species of Plantago (P. arenaria, P. coronopus, P. psyllium, P. indica, P. serraria and P. lanceolata). Of 30 primers, only $20(66 \%)$ showed amplification in at least one of the allied Plantago species during cross-species amplification (Table 5). Cross-species amplification of these novel SSRs in other sections varied, and a maximum of $85 \%$ cross-species transferability was noticed with $P$. arenaria and P. lanceolata, followed by P. coronopus and P. serraria (80\%) and P. psyllium and P. indica (75\%). The present report on the cross-species transferability was comparable with earlier reports on different crop species, such as cotton [57] and sugarcane [58]. The high rate of transferability suggests that the SSR flanking regions of the sequences identified in P. ovata are well conserved among the Plantago species. However, the results are not in congruence with Kotwal et al., 2013, where the limited transferability of the primers from P. major to Plantago species was observed; although, primers based on unrelated genera, like Malus and Phaseolus, showed successful cross-species amplification in other species of Plantago [59].

Table 5. SSR cross-amplification in other species of Plantago based on the presence $(+)$ /absence $(-)$ of the amplified product.

\begin{tabular}{|c|c|c|c|c|c|c|}
\hline Primer & P. arneria & P. coronopus & P. psyllium & P. indica & P. serraria & P. lanceolata \\
\hline APOM 3 & - & + & - & - & + & + \\
\hline APOM 4 & + & + & + & + & + & + \\
\hline APOM 8 & + & + & + & + & + & + \\
\hline APOM 9 & + & + & + & + & + & + \\
\hline APOM 10 & + & + & + & + & + & + \\
\hline APOM 12 & + & + & + & + & + & + \\
\hline APOM 13 & + & + & + & + & + & + \\
\hline APOM 14 & - & + & - & - & + & + \\
\hline APOM 15 & + & + & + & + & + & + \\
\hline APOM 17 & + & + & + & + & + & + \\
\hline APOM 20 & + & - & - & - & - & - \\
\hline APOM 21 & + & - & - & - & - & - \\
\hline APOM 23 & + & + & + & + & + & + \\
\hline APOM 25-1 & - & + & - & - & + & + \\
\hline APOM 25-2 & + & - & + & + & - & - \\
\hline APOM 27 & - & + & + & + & + & + \\
\hline APOM 29 & + & + & + & + & + & + \\
\hline APOM 31 & + & + & + & + & + & + \\
\hline APOM 34 & + & + & + & + & + & + \\
\hline APOM 36 & + & + & + & + & + & + \\
\hline APOM 37 & + & - & + & - & - & + \\
\hline Total & 17 & 16 & 15 & 15 & 16 & 17 \\
\hline $\begin{array}{c}\text { Transferability (\%) } \\
\text { Percentage }\end{array}$ & 85 & 80 & 75 & 75 & 80 & 85 \\
\hline
\end{tabular}

+, Presence of amplified product; -, absence of amplified product. 


\subsection{SSR Marker Scoring and Data Analysis}

The authentic identification of taxa is necessary for the commercial importance of Plantago and the protection of the intellectual property rights of breeders and farmers [14]. Therefore, six highly diverse genotypes of Plantago ovata and one genotype each from six allied species were fingerprinted with 30 SSRs. The present results showed that there is a very low polymorphism within P. ovata, as all SSRs were monomorphic. During the analysis, SSRs could clearly differentiate all of the species of Plantago used for study.

Jaccard's similarity coefficients among all pair-wise combinations of genotypes ranged from 0.38 to one, with a mean genetic similarity of 0.68 . The dendrogram based on UPGMA analysis separated all of the genotypes into six groups at an average cut-off value of 0.79 (Figure 3). Six genotypes of Plantago ovata clustered into group one, and the rest of the genotypes were clustered in the other two. The first major cluster was divided into two minor clusters, out of which one minor cluster had one of the two early maturing genotypes, DPO14 of $P$. ovata having $94 \%$ similarity between them. Cluster I with only $P$. ovata was further sub-clustered, comprising GI-3, GI-2, RI-89 and EC124345 with 98.6\% similarity. The accession EC123345 is highly resistant to downy mildew and is indigenous to Pakistan, hence being very distinct. However, this could not be clearly detected by SSR. Cluster II was comprised of P. arenaria, P. psyllium and P. indica; Cluster III was comprised of P. coronopus, $P$. serraria and $P$. lanceolata. The clustering pattern of the dendrogram corroborates the nature of genotypes GI-3, GI-2 and RI-89, which are developed by mutation breeding and possess elite characteristics, such as the EC124345 line, which is downy mildew resistant. The pattern of clustering of other species corresponds with earlier studies of [14]. In the second cluster, P. arneria alone showed a similarity index of about $63 \%$ and $78 \%$ with $P$. psyllium and $P$. indica, respectively. The placement of $P$. serraria and $P$. lanceolata in the present dendrogram does not line up with earlier findings [14], as both of these species belong to different subgenus's, coronopus and albicans, respectively; hence $P$. serraria should have been therefore clustered with species in the fourth cluster.

Figure 3. Dendrogram based on UPGMA clustering of 12 genotypes of isabgol using SSR markers.

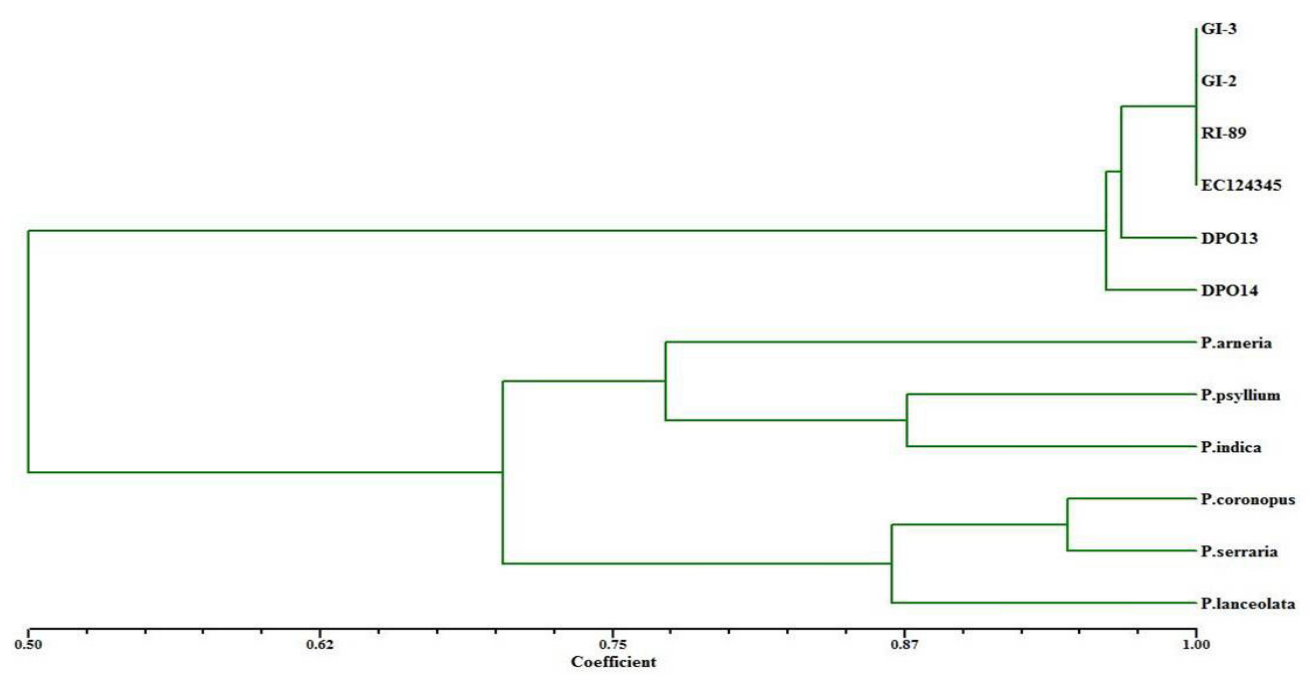


A RAPD analysis of different Plantago species by Singh et al., 2009, showed a high level of polymorphism at the species level [53]. However, within species, only a low level of polymorphism was observed. Additionally, from the RAPD study, the accessions were not differentiated, but intra-specific differences recorded in all three species were much less in comparison with inter-specific diversity.

The study is mainly aimed at the development of genomic resources and not at genetic diversity. The newly developed SSR markers showed amplification in Plantago ovata genotypes and cross-amplification in other species, although polymorphism was not seen. The study preliminarily confirms that less variability/diversity exits in Plantago spp., and for an in-depth conformation, more SSR markers need to be screened.

\section{Acknowledgments}

This work was financially supported by Gujarat State Biotechnology Mission, Department of Science and Technology, Government of Gujarat, India. The authors are thankful to Maheshbhai A. Patel, Associate Research Scientist, Medicinal and Aromatic Research Centre, Anand Agricultural University, Anand, for providing the germplasm.

\section{Author Contributions}

R.S.F., C.J. and S.K. guided the experiment and edited the final version of manuscript. K.K., A.P., A.S. and J.M. conceived and designed the study, performed the experiment and analyzed the data.

\section{Conflicts of Interest}

The authors declare no conflicts of interest.

\section{References}

1. Dalal, K.C.; Sriram, S. Psyllium. In Advances in Horticulture. 11. Medicinal and Aromatic Plants; Chadha, K.L., Gupta, R., Eds.; Malhotra Publishing House: New Delhi, Indian, 1995; Volume 11, pp. 575-604.

2. Chandler, C. Improvement of Plantago for mucilage production and growth in United States. Contr. Boyce Thomoson. Inst. 1954, 17, 495-505.

3. Zargari, A. Medicinal Plants, 4th ed.; University of Tehran: Tehran, Iran, 1990; Volume 4, pp. $18-19$.

4. Ansari, S.H.; Ali, M. Chemical, pharmacological and clinical evaluation of Plantago ovata Forsk. Hamdard Med. 1996, 39, 63-85.

5. Patel, A.; Saravanan, R. Screening of Plantago species for physiological parameters in relation to seed yield. Electron. J. Plant Breed. 2010, 1, 1454-1460.

6. Dhar, M.K.; Kaul, S.; Friebe, B.; Gill, B.S. Chromosome identification in Plantago ovata Forsk. through C-banding and FISH. Curr. Sci. 2002, 83, 150-152.

7. Punia, M.S.; Sharma, G.D.; Verma, P.K. Genetics and breeding of Plantago ovata Forsk. A review. Inter. J. Trop. Agri. 1985, 3, 255-264. 
8. Lal, R.K.; Sharma, J.R.; Misra, H.O. Induced variability and varietal selection in Isabgol (Plantago ovata). J. Med. Arom. Plant Sci. 1999, 21, 34-37.

9. Mittal, S.P.; Bhagat, N.R.; Maheshwari, M.L. Improvement of Plantago ovata Forsk. through tetraploidy and mutation breeding. Indian J. Agric. Sci. 1975, 45, 426-429.

10. Bhagat, N.R.; Hardas, M.W. Studies on induce and natural variation in Plantago ovata Forsk. Indian Drugs 1980, 17, 376-380.

11. Bhan, A.; Dhar, M.K.; Langer, A. Genetic diversity among Plantagos XX. A tetraploid Plantago lagopus L. Cytologia 1990, 55, 511-517.

12. Dalal, K.C.; Sriram, S. Psyllium. In Advances in Horticulture medicinal and Aromatic Plants; Chaddha, K.L., Gupta, R., Eds.; Malhotra Publishing House: New Delhi, India, 1995; Volume 2, pp. 575-604.

13. Dhar, M.K.; Kaul, S.; Sareen, S.; Koul, A.K. Plantago ovata: Genetic diversity, cultivation, utilization and chemistry. Plant Gen. Resour. 2005, 3, 252-263.

14. Samantaray, S.; Dhagat, U.M.; Maiti, S. Evaluation of genetic relationships in Plantago species using Random Amplified Polymorphic DNA (RAPD) markers. Plant Biotechnol. 2010, 27, 297-303.

15. Vala, A.G.; Fougat, R.S.; Jadeja, G.C. Genetic diversity of Plantago ovata Forsk. through RAPD markers. Elec. J. Plant Breed. 2011, 2, 592-596.

16. Rohila, A.K.; Kumar, M.; Sindhu, A.; Boora, K.S. Genetic diversity analysis of the medicinal herb Plantago ovata (Forsk.). Afr. J. Biotechnol. 2012, 11, 15835-15842.

17. Wolff, K.; Morgan, R.M. PCR markers distinguish Plantago major subspecies. Theor. Appl. Genet. 1998, 96, 282-286.

18. Wolff, K.; Morgan, R.M.; Davison, A.W. Patterns of molecular genetic variation in Plantago major and P. intermedia in relation to ozone resistance. New Phytologist. 2000, 145, 501-509.

19. Kaswan, V.; Joshi, A.; Maloo, S.R. Assessment of genetic diversity in Isabgol (Plantago ovata Forsk.) using random amplified polymorphic DNA (RAPD) and inter-simple sequence repeat (ISSR) markers for developing crop improvement strategies. Afr. J. Biotechnol 2013, 12, 3622-3635.

20. Koorevaar, G.N.; Ivanovic, S.; van Damme, J.M.M.; Koelewijn, H.P.; van'T Westende, W.P.C.; Smulders, M.J.M.; Vosman, B. Dinucleotide repeat microsatellite markers for buck's-horn Plantain (Plantago coronopus). Mol. Ecol. Note. 2002, 2, 524-526.

21. Hale, M.L.; Wolff, K. Polymorphic microsatellite loci in Plantago lanceolata. Mol. Ecol. Notes. 2003, 3, 134-135.

22. Squirrell, J.; Wolff, K. Isolation of polymorphic microsatellite loci in Plantago major and P. intermedia. Mol. Ecol. Notes. 2001, 1, 179-181.

23. Parida, S.K.; Kalia, S.K.; Kaul, S.; Dalal, V.; Hemaprabha, G.; Selvi, A.; Pandit, A.; Singh, A.; Gaikwad, K.; Sharma, T.R.; et al. Informative genomic microsatellite markers for efficient genotyping applications in sugarcane. Theor. Appl. Genet. 2009, 118, 327-338.

24. Zane, L.; Bargelloni, L.; Patarnello, T. Strategies for microsatellites isolation, a review. Mol. Ecol. 2002, 44, 1-16.

25. Schadt, E.E.; Turner, S.; Kasarskis, A. A window into third-generation sequencing. Hum. Mol. Gen. 2010, 19, R227-R240.

26. Doyle, J.J.; Doyle, J.L. Isolation of Plant DNA from Fresh Tissue. Focus 1990, 12, 13-15. 
27. Gnirke, A.; Melnikov, A.; Maguire, J.; Rogov, P.; LeProust, E.M.; Brockman, W.; Fennell, T.; Giannoukos, G.; Fisher, S.; Russ, C.; et al. Solution hybrid selection with ultra-long oligonucleotides for massively parallel targeted sequencing. Nat. Biotechnol 2009, 27, 182-189.

28. Thiel, T.; Michalek, W.; Varshney, R.K.; Graner, A. Exploiting, EST databases for the development and characterization of gene-derived SSR-markers in barley (Hordeum vulgare L.) Theor. Appl. Genet 2003, 106, 411-422.

29. Perl-based Microsatellite Search Module. Available online: http://pgrc.ipk-gatersleben.de/Misa (accessed on 1 December 2012).

30. Senthilvel, S.; Jayashree, B.; Mahalakshmi, V.; Kumar, P.S.; Nakka, S.; Nepolean, T.; Hash, C.T. Development and mapping of simple sequence repeat markers for pearl millet from data mining of expressed sequence tags. BMC Plant Biol. 2008, 8, 119.

31. Rozen, S.; Skaletsky, H.J. Primer3 on the WWW for general users and for biologist programmers. In Methods in Molecular Biology; Misener, S., Krawetz, S.A., Eds.; Humana Press Inc.: Totowa, NJ, USA, 2000; pp. 365-386.

32. Integrated DNA Technologies. Available online: http://www.idtdna.com/pages/scitools (accessed on 15 December 2012).

33. Rohlf, F.J. NTSYS-PC Numerical Taxonomy and Multivariate Analysis System, Version 2.2.; State University of New York: Stony brook, NY, USA, 1994.

34. Anderson, J.A.; Churchill, G.A.; Autrique, J.E.; Tanksley, S.D.; Sorrells, M.E. Optimizing parental selection for genetic linkage maps. Genome 1993, 36, 181-186.

35. Rafalski, J.A.; Vogel, J.M.; Morgante, M.; Powell, W.; Andre, C.; Tingey, S.V. Generating and using DNA markers in plants. In Non-Mammalian Genomic Analysis: A Practical Guide; Birren, B., Lai, E., Eds.; Academic: San Diego, CA, USA, 1996; pp. 75-135.

36. Santana, Q.; Coetzee, M.; Steenkamp, E.; Mlonyeni, O.; Hammond, G.; Wingfield, M.; Wingfield, B. Microsatellite discovery by deep sequencing of enriched genomic libraries. Biotechniques 2009, 46, 217-223.

37. Gardner, M.G.; Fitch, A.J.; Bertozzi, T.; Lowe, A.J. Rise of the machines recommendations for ecologists when using next generation sequencing for microsatellite development. Mol. Ecol. Resour. 2011, 11, 1093-1101.

38. Elliott, C.P.; Enriqht, N.J.; Allcock, R.J.; Gardner, M.G.; Meglécz, E.; Anthony, J.; Krauss, S.L. Microsatellite markers from the Ion Torrent: A multi-species contrast to 454 shotgun sequencing. Mol. Ecol. Resour. 2014, 14, 554-568.

39. Ellegren, H. Microsatellites: Simple sequences with complex evolution. Nat. Rev. Genet. 2004, 6, 435-445.

40. Temnykh, S.; DeClerck, G.; Lukashova, A.; Lipovich, L.; Cartinhour, S.; McCouch, S. Computational and experimental analysis of microsatellites in rice (Oryza sativa L.): Frequency, length variation, transposon associations, and genetic marker potential. Genome Res. 2001, 11, 1441-1452.

41. Pupko, T.; Graur, D. Evolution of microsatellites in the yeast Saccharomyces cerevisiae: Role of length and number of repeated units. J. Mol. Evol. 1999, 48, 313-316.

42. Zhao, Z.; Guo, C.; Sutharzan, S.; Li, P.; Echt, C.S.; Zhang, J.; Liang, C. Genome-wide analysis of tandem repeats in plants and green algae. G3(Bethesda) 2014, 4, 67-78. 
43. Liu, S.R.; Li, W.Y.; Long, D.; Hu, C.G.; Zhang, J.Z. Development and characterization of genomic and expressed SSRs in Citrus by genome-wide analysis. PLoS One 2013, 8, e75149.

44. Cavagnaro, P.F.; Senalik, D.A.; Yang, L.; Simon, P.W.; Harkins, T.T.; Kodira, C.D.; Huang, S.; Weng, Y. Genome-wide characterization of simple sequence repeats in cucumber (Cucumis sativus L.). BMC Genomics 2010, 11, 569.

45. Sonah, H.; Deshmukh, R.K.; Sharma, A.; Singh, V.P.; Gupta, D.K.; Gacche, R.N.; Rana, J.C.; Singh, N.K.; Sharma, T.R. Genome-wide distribution and organization of microsatellites in plants, an insight into marker development in Brachypodium. PLoS One 2011, 6, e21298.

46. Lin, H.; Chiang, C.Y.; Chang, S.B.; Kuoh, C.S. Development of Simple Sequence Repeats (SRR) markers in Setaria italica (Poaceae) and cross-amplification in related species. Int. J. Mol. Sci. 2011, 12, 7835-7845.

47. Dhar, M.K.; Fuchs, J.; Houben, A. Distribution of eu- and heterochromatin in Plantago ovata. Cytogenet. Gen. Res. 2009, 125, 235-240.

48. Yonemaru, J.; Ando, T.; Mizubayashi, T.; Kasuga, S.; Matsumoto, T.; Yano, M. Development of genome-wide simple sequence repeat markers using whole-genome shotgun sequences of sorghum (Sorghum bicolor (L.) Moench). DNA Res. 2009, 16, 187-193.

49. Katti, M.V.; Ranjekar, P.K.; Gupta, V.S. Differential distribution of simple sequence repeats in eukaryotic genome sequences. Mol. Biol. Evol. 2001, 18, 1161-1167.

50. Kalia, R.K.; Rai, M.K.; Kalia, S.; Singh, R.; Dhawan, A.K. Microsatellite markers, an overview of the recent progress in plants. Euphytica 2011, 177, 309-334.

51. Mun, J.; Kim, D.J.; Choi, H.K.; Gish, J.; Debellé, F.; Mudge, J.; Denny, R.; Endré, G.; Saurat, O.; Dudez, A.M.; et al. Distribution of microsatellites in the genome of Medicago truncatula: A resource of genetic markers that integrate genetic and physical maps. Genetics 2006, 172, 2541-2555.

52. Victoria, F.C.; Maia, L.; Oliveira, A.C. In silico comparative analysis of SSR markers in plants. BMC Plant Biol. 2011, 11, 15.

53. Singh, N.; Lal, R.K.; Shasany, A.K. Phenotypic and RAPD diversity among 80 germplasm accessions of the medicinal plant Isabgol (Plantago ovata, Plantaginaceae). Genet. Mol. Res. 2009, 8, 1273-1284.

54. Liebhard, R.; Gianfranceschi, L.; Koller, B.; Ryder, C.D.; Tarchini, R.; van de Weg, E.; Gessler, C. Development and characterization of 140 new microsatellites in apple (Malus X domestica Borkh.). Mol. Breed. 2002, 10, 217-241.

55. Yamamoto, T.; Srivastava, A.; Rai, K.M.; Ranjan, A.; Singh, S.K.; Nisar, T.; Srivastava, M.; Bag, S.K.; Mantri, S.; Asif, M.H.; et al. Identification of quince varieties using SSR markers developed from pear and apple. Breed. Sci. 2004, 54, 239-244.

56. Dayanandan, S.; Bawa, K.; Kesseli, R. Conservation of microsatellites among tropical trees (Leguminosae). Amer. J. Bot. 1997, 84, 1658-1663.

57. Jena, S.N.; Srivastava, A.; Rai, K.M.; Ranjan, A.; Singh, S.K.; Nisar, T.; Srivastava, M.; Bag, S.K.; Mantri, S.; Asif, M.H.; et al. Development and characterization of genomic and expressed SSRs for levant cotton (Gossypium herbaceum L.). Theor. Appl. Genet. 2012, 124, 565-576.

58. Singh, R.K. Development, cross-species/genera transferability of novel EST-SSR markers and their utility in revealing population structure and genetic diversity in sugarcane. Gene 2013, 524, 309-329. 
59. Kotwal, S.; Dhar, M.K.; Kour, B.; Raj, K.; Kaul, S. Molecular markers unravel intraspecific and interspecific genetic variability in Plantago ovata and some of its wild allies. J. Genet. 2013, 92, 293-298.

(C) 2014 by the authors; licensee MDPI, Basel, Switzerland. This article is an open access article distributed under the terms and conditions of the Creative Commons Attribution license (http://creativecommons.org/licenses/by/3.0/). 